Revista Universo Contábil, ISSN 1809-3337
Blumenau, v. 14, n. 4, p. 137-159, out./dez., 2018
Disponível em www.furb.br/universocontabil

\title{
DETERMINANTES DO DESEMPENHO DE ECOEFICIÊNCIA CORPORATIVA E A CRIAÇÃO DE VALOR ÀS EMPRESAS BRASILEIRAS1
}

\section{DETERMINANTS OF CORPORATE ECO-EFFICIENCY PERFORMANCE AND VALUE CREATION FOR BRAZILIAN COMPANIES}

\section{DETERMINANTES DEL DESEMPEÑO DE ECOEFICIENCIA CORPORATIVA Y LA CREACIÓN DE VALOR A LAS EMPRESAS BRASILEÑAS}

\author{
Maria Rafaela de Oliveira Freitas \\ Mestre em Administração e Controladoria pela Universidade Federal do Ceará \\ Analista Judiciário do Tribunal de Justiça do Estado do Ceará \\ Endereço: Av. General Afonso Albuquerque Lima, sn, Cambeba \\ CEP: 60830-120- Fortaleza - CE - Brasil \\ E-mail: rafitadeut@gmail.com \\ Telefone: (85) 3207-7646
}

Jackeline Lucas Souza Doutorado em Engenharia Civil - Recursos Hídricos pela Universidade Federal do Ceará Professora do Departamento de Ciências Contábeis da Universidade Federal do Ceará Endereço: FEAAC-UFC, Av. da Universidade, 2486, Benfica CEP: 60020-180 - Fortaleza, CE - Brasil E-mail: jackeline.souza@hotmail.com Telefone: (85) 3366-7802

Raimundo Eduardo Silveira Fontenele Doutorado em Ciências Econômicas pela Université de Paris XIII Professor do PPG em Administração e Controladoria da Universidade Federal do Ceará Endereço: FEAAC-UFC, Avenida da Universidade, 2431, Benfica CEP: 60020-180 - Fortaleza, CE - Brasil E-mail: eduardo@ufc.br Telefone: (85) 3366-7800

Sílvia Maria Dias Pedro Rebouças

Pós-Doc em Métodos Quantitativos Aplicados à Economia e à Gestão pela Universidade do Algarve Doutorado em Estatística e Investigação Operacional pela Universidade de Lisboa Professora do PPG em Administração e Controladoria da Universidade Federal do Ceará Endereço: FEAAC-UFC, Avenida da Universidade, 2431, Benfica CEP: 60020-180 - Fortaleza, CE - Brasil E-mail: smdpedro@gmail.com Telefone: (85) 3366-7803

\footnotetext{
${ }^{1}$ Artigo recebido em 24/09/2018. Revisado por pares em 13/03/2019. Reformulado em 29/03/2019. Recomendado para publicação em 11/04/2019 por Moacir M. Rodrigues Jr. Publicado em 13/05/2019. Organização responsável pelo periódico: FURB.
} 


\section{RESUMO}

O presente estudo investiga a influência de diversas características da firma- que inclui os efeitos das oportunidades de crescimento, tamanho, endividamento, impacto ambiental, melhores práticas de governança e melhores práticas de sustentabilidade - sobre o desempenho de ecoeficiência corporativa de empresas brasileiras, obtido através da metodologia de mensuração de ecoeficiência proposta por Nikolaou e Matrakoukas (2016). O trabalho foi desenvolvido sob o aporte teórico da Visão Baseada em Recursos (VBR) no tocante à relação entre desempenho de ecoeficiência e criação de valor da empresa, representada por suas oportunidades de crescimento. Com uma amostra que reúne 94 empresas listadas na B3 em 2016 que divulgaram relatórios de sustentabilidade nas diretrizes da Global Reporting Initiative (GRI), foram realizadas análise de conteúdo dos relatórios de sustentabilidade das empresas, assim como análise quantitativa através de testes de diferença de médias, correlação e regressão linear múltipla. Os resultados apontam que as oportunidades de crescimento da empresa influenciam positivamente o desempenho de ecoeficiência corporativa, convergindo para o que postula a VBR. Por outro lado, o nível de endividamento da empresa teve influência negativa sobre o desempenho de ecoeficiência, sinalizando a existência de um trade off entre endividamento e ecoeficiência corporativa. A pesquisa contribui para a literatura nacional ao estudar a ecoeficiência corporativa em um nível maior de escala, evidenciando sua relação com a criação de valor da empresa brasileira.

Palavras-chave: Ecoeficiência corporativa; Criação de valor; Desempenho ambiental.

\section{ABSTRACT}

The present study investigates the influence of several characteristics of the firm - including the effects of opportunities for growth, size, indebtedness, environmental impact, best governance practices and best practices of sustainability - on the corporate eco-efficiency performance of Brazilian companies obtained through of the eco-efficiency measurement methodology proposed by Nikolaou and Matrakoukas (2016). The work was developed under the theoretical support of the Resource Based View (VBR) regarding the relationship between eco-efficiency and value creation of the company, represented by its growth opportunities. With a sample of 94 companies listed on the B3 that published sustainability reports in the guidelines of the Global Reporting Initiative (GRI) in 2016, we performed content analysis of company sustainability reports, as well as quantitative analysis through means difference tests, correlation and multiple linear regression. The results indicate that the company's growth opportunities have a positive influence on corporate eco-efficiency performance, converging to what the VBR proposes. On the other hand, the level of indebtedness of the company had a negative impact on eco-efficiency performance, signaling the existence of a trade off between indebtedness and corporate eco-efficiency. The research contributes to the national literature by studying corporate eco-efficiency at a higher level of scale, evidencing its relation to the value creation of the Brazilian company.

Keywords: Corporate eco-efficiency; Value creation; Environmental performance.

\section{RESUMEN}

El presente estudio investiga la influencia de diversas características de la firma, que incluye los efectos de las oportunidades de crecimiento, tamaño, endeudamiento, impacto ambiental, mejores prácticas de gobernanza y mejores prácticas de sustentabilidad- sobre el desempeño de ecoeficiencia corporativa de empresas brasileñas, obtenido a través de la metodología de medición de ecoeficiencia propuesta por Nikolaou y Matrakoukas (2016). El trabajo fue desarrollado bajo el aporte teórico de la Visión Basada en Recursos (VBR) en lo referente a la relación entre desempeño de ecoeficiencia y creación de valor de la empresa, representada por 
sus oportunidades de crecimiento. Con una muestra que reúne a 94 empresas listadas en la B3 en 2016 que divulgaron informes de sostenibilidad en las directrices de la Global Reporting Initiative (GRI), se realizaron análisis de contenido de los informes de sostenibilidad de las empresas, así como análisis cuantitativo a través de pruebas de diferencia de promedios, correlación y regresión lineal múltiple. Los resultados apuntan que las oportunidades de crecimiento de la empresa influencian positivamente el desempeño de ecoeficiencia corporativa, convergiendo para lo que postula la VBR. Por otro lado, el nivel de endeudamiento de la empresa tuvo un impacto negativo sobre el desempeño de ecoeficiencia, señalando la existencia de un trade off entre endeudamiento y ecoeficiencia corporativa. La investigación contribuye a la literatura nacional al estudiar la ecoeficiencia corporativa en un nivel mayor de escala, evidenciando su relación con la creación de valor de la empresa brasileña.

Palabras clave: Ecoeficiencia corporativa; Creación de valor; Rendimiento ambiental.

\section{INTRODUÇÃO}

O conceito de desenvolvimento sustentável consolidou-se mundialmente a partir das preocupações ambientais e da necessidade de se buscar estratégias favoráveis à sustentabilidade socioeconômica e ambiental (RODRIGUES; DUARTE, 2011), com destaque aos importantes eventos mundiais, iniciados com a Conferência de Estocolmo em 1972, a publicação do relatório Our Common Future, conhecido mundialmente como Relatório Brundtland, em 1987, e a Conferência das Nações Unidas sobre o Meio Ambiente e o Desenvolvimento-ECO 92 em 1992 (ELKINGTON, 1997). A partir dessa época, tem-se observado um crescimento significativo de organizações preocupadas em alinhar suas estratégias às causas do meio ambiente, à medida em que os movimentos ambientais se aproximaram do contexto organizacional (LINS; ZYLBERSZTAJN, 2010).

Em meio ao dilema de criação de valor almejado pelas empresas e de preocupações com impactos causados ao meio ambiente, surge o conceito de ecoeficiência, desenvolvido para alinhar interesses empresariais à preservação do meio ambiente, cuja função principal é buscar agregar valor econômico e otimizar o consumo dos recursos naturais (SAVITZ; WEBER, 2006).

A ecoeficiência é definida como a relação entre aspectos econômicos e ambientais no nível de empresa ou produto, que proporciona serviços e produtos competitivos para satisfazer as necessidades humanas e trazer qualidade de vida, enquanto se reduz progressivamente impactos ecológicos e a intensidade de utilização de recursos (LEHNI, 2000). Além disso, a ecoeficiência, ao convergir para todas as operações da firma, pode ser vista pela empresa como um indutor de valor ao gerar oportunidades de crescimento em seus negócios (VERFAILLIE; BIDWELL, 2000). Nesse sentido, sob a perspectiva da Visão Baseada em Recursos (VBR), além de contribuir para manter a empresa mais engajada com suas estratégias de gestão ambiental, a ecoeficiência promove a posição competitiva da empresa no mercado (GUENSTER et al., 2011).

A discussão sobre ecoeficiência no cenário nacional ainda é incipiente, principalmente quando se busca relacioná-la com a criação de valor à empresa brasileira, considerando maior gama de setores e empresas que operam em grande escala no mercado. Grande parte dos trabalhos existentes sobre ecoeficiência envolvem estudos de casos que evidenciam metodologias individualizadas nas empresas, nos setores ou nos produtos, inviabilizando comparações entre as mesmas (MUNCK; OLIVEIRA; BANSI, 2011; SOUSA; ANDRADE; CAMARA, 2013; COLARES; MATIAS, 2014; OLIVEIRA; CAMANHO; ZANELLA, 2017).

Alguns estudos na literatura estrangeira apontam que pode haver um ciclo virtuoso entre ecoeficiência e criação de valor, sendo constatada uma relação positiva tanto no cenário de empresas norte americanas (GUENSTER et al., 2011; JACOBS; SINGHAL; SUBRAMANIAN, 2010; SHARFMAN; FERNANDO, 2008), quanto europeias (GRUPTA; 
BENSON, 2011), enquanto se observa uma escassez de estudos na literatura nacional sobre a investigação desse possível ciclo virtuoso no ambiente da empresa brasileira.

Neste contexto, ao contribuir para preencher essa lacuna na literatura nacional sobre ecoeficiência em nível maior de escala, relacionada à criação de valor para empresa, o presente estudo se propõe a responder à seguinte questão de pesquisa: Quais os determinantes do desempenho de ecoeficiência corporativa das empresas brasileiras de capital aberto? O objetivo geral consiste em identificar os fatores determinantes da ecoeficiência corporativa de empresas brasileiras de capital aberto.

Este estudo contribui na medida em que permite uma comparabilidade abrangente entre empresas brasileiras, tendo em vista a necessidade de se ter um retrato da ecoeficiência dessas empresas, dando destaque à sua relação com a criação de valor, a partir da utilização da metodologia de mensuração de ecoeficiência proposta por Nikolaou e Matrakoukas (2016), que relaciona desempenho econômico-financeiro da empresa com informações de seu desempenho ambiental, obtidas através de indicadores constantes em relatórios de sustentabilidade.

\section{REFERENCIAL TEÓRICO E HIPÓTESES}

No embasamento teórico deste estudo, são introduzidos e contextualizados temas relevantes atinentes à ecoeficiência corporativa, desempenho empresarial e criação de valor, além de investigar, através da proposição das hipóteses do estudo, a influência de alguns atributos da empresa sobre desempenho de ecoeficiência.

\subsection{Ecoeficiência corporativa}

A gestão ambiental tem emergido como um fator estratégico essencial no contexto empresarial. Segundo Haden, Oyler e Humphreys (2009) e Nawrocka e Parker (2009), esta estratégia consiste num processo de ampla organização da aplicação da inovação para alcançar a sustentabilidade, responsabilidade social, vantagem competitiva e redução de desperdício.

Além disso, Anacleto et al. (2012) destacam que, nos últimos anos, tem-se constatado, a partir de estudos e experiências, que para obter vantagem competitiva, assim como alcançar desenvolvimento sustentável, é necessário que as organizações maximizem o uso de práticas ambientais sustentáveis. Nesse sentido, a ecoeficiência tem ganhado destaque como uma das principais intervenções orientadas para a melhoria do desempenho ambiental (SALVADOR; GLASSON; PIPER, 2000; GIANNETTI et al., 2008; BORGES; HAUSER-DAVIS; OLIVEIRA, 2011).

Desse modo, a partir do estabelecimento da gestão ambiental como fator estratégico da empresa, surge a ecoeficiência como uma filosofia emergente da sustentabilidade organizacional que serve como ferramenta para aliar o desenvolvimento econômico com o ambiental. Esse conceito de ecoeficiência apresentou uma grande experimentação e consolidação uma década após a conferência das Nações Unidas sobre ambiente e desenvolvimento ocorrida em 1992.

Dodic' et al. (2010) destacam que a ecoeficiência é um conceito promovido pelo World Business Council for Sustainable Development, que envolve a entrega de produtos e serviços com preços competitivos que satisfazem as necessidades humanas e fornecem qualidade de vida, ao mesmo tempo em que reduzem os impactos ecológicos e a intensidade de recursos, de acordo com a capacidade estimada da Terra.

Segundo Guenster et al. (2011), o conceito de ecoeficiência corporativa reflete a governança ambiental da empresa além do que é indicado pelas políticas elementares de conformidade ambiental e controle da poluição, o que reflete a capacidade da ecoeficiência de criar valor para a empresa com menos recursos ambientais, resultando com isso em menor impacto ambiental. 
Nesse sentido, a ecoeficiência é vista como um processo no âmbito da organização que, de acordo com Schmidheiny (1996) e Helminen (2000), representa um processo direcionador dos investimentos e do desenvolvimento de tecnologias para gerar valor ao acionista, minimizar o consumo de recursos e reduzir o desperdício e a poluição.

Diante do exposto, a partir da contribuição de autores como Elkington (1997), Savitz e Weber (2006), e Pedroso et al. (2012), o conceito de ecoeficiência pode ser sintetizado como um componente da sustentabilidade organizacional que combina o desenvolvimento ambiental com o desenvolvimento econômico, ao passo em que reduz os impactos ambientais.

Portanto, negócios ecoeficientes reduziriam o desperdício e obteriam mais lucros, uma vez que encorajariam empresas a procurar melhorias ambientais que potencializem, paralelamente, benefícios econômicos, permitindo que se tornem tão mais responsáveis do ponto de vista ambiental, quanto mais lucrativas.

\subsection{Desempenho empresarial, criação de valor e determinantes da ecoeficiência corporativa}

Tradicionalmente, o desempenho empresarial esteve ligado essencialmente à capacidade de a organização maximizar lucros sem se preocupar com qualquer outro critério (SCHMIDT; SANTOS; MARTINS, 2006). No entanto, houve a necessidade de ampliar o conceito de desempenho empresarial para além das considerações que passam pelos indicadores econômicos tradicionais, incluindo medidas de desempenho social e ambiental ligadas à satisfação dos interesses de múltiplos stakeholders, que incluem, entre outros, satisfação e retenção de clientes, motivação dos funcionários, preocupações com comunidade e meio ambiente (CARROL, 1979; KAPLAN; NORTON, 1997).

Destaca-se que a criação de valor é identificada como consequência das várias estratégias e políticas adotadas pela gestão, o que remete à necessidade de um direcionamento dos esforços da organização no objetivo primário da criação de valor (ASSAF NETO, 2008). Nesse sentido, as decisões da empresa devem ser orientadas para os direcionadores de valor adotados pela empresa, e estes precisam ser avaliados quanto à eficiência no objetivo maior, que é a criação de valor para o acionista, que, dependendo do retorno obtido, poderão reaplicar seus recursos ou optar pelo desinvestimento da opção que destrói a sua riqueza.

De uma forma geral, o entendimento da criação de valor é facilitado a partir da seguinte equação simplificada apresentada por Assaf Neto (2005): ocorrerá a criação de valor quando as receitas operacionais superarem todos os dispêndios (custos e despesas) incorridos, inclusive o custo de oportunidade. Segundo Assaf Neto (2005), o modelo de valor prioriza essencialmente o longo prazo, a continuidade da empresa, sua capacidade de competir, ajustarse aos mercados em transformação e agregar riqueza a seus proprietários. Dessa forma, os esforços de toda a organização precisam ser canalizados para assegurar o alcance destes objetivos.

A comunidade acadêmica tem postulado diversos modelos teórico-empíricos e hipóteses para relacionar responsabilidade corporativa ambiental e desempenho econômicofinanceiro da empresa, principalmente com a intenção de fornecer uma estrutura que alinhe a sustentabilidade empresarial com a criação de valor aos acionistas (ULLMAN, 1985; HART; AHUJA, 1996; GRIFFIN; MAHON, 1997; MARGOLIS; WALSH, 2003; CORBETT; KLASSEN, 2006). Essa relação que atrela investimentos ambientais a um melhor desempenho econômico-financeiro da empresa encontra suporte na teoria da Visão Baseada em Recursos, segundo a qual a decisão estratégica da firma de empreender atividades de responsabilidade socioambiental fazem as empresas investirem em ativos valiosos, raros e insubstituíveis, como liderança e reputação corporativa que, por serem de difícil imitação, podem resultar em vantagem competitiva e diferenciação sobre os concorrentes (ABREU et al., 2008; COELHO; PAVÃO; MELO, 2009). 
Nesse sentido, com base na teoria da Visão Baseada em Recursos, Guenster et al. (2011) destacam que a ecoeficiência, como uma governança ambiental proativa, representa uma fonte de benefícios financeiros exclusivos da empresa e difíceis de obter pelos concorrentes. Além disso, Sharfman e Fernando (2008) argumentam que as empresas que desenvolvem uma estratégia que melhora sua gestão de risco ambiental tendem a ser recompensadas pelos mercados financeiros, em que a ecoeficiência torna-se vitrine ao desenvolvimento dos mercados.

Desse modo, o próprio construto de ecoeficiência, que envolve a relação entre desempenho ambiental e financeiro, torna pertinente a investigação de sua relação com a criação de valor para a empresa, indicando um ciclo virtuoso entre ecoeficiência, vantagem competitiva e a consequente criação de valor, assim como constatado por Guenster et al. (2011), que encontraram uma relação positiva do desempenho de ecoeficiência com o desempenho operacional e com o valor de mercado de empresas norte americanas.

Resultados similares também foram evidenciados por Jacobs, Singhal e Subramanian (2010), que encontraram reação de mercado positiva com o anúncio de causas ambientais filantrópicas pelas empresas norte americanas e europeias, e por Grupta e Benson (2011), cujos achados apontam que empresas sustentáveis são vistas como altamente competitivas em seus setores.

Seguindo a evidência encontrada de que melhor desempenho de ecoeficiência corporativa está atrelada à maior vantagem competitiva, levando as empresas que apresentam maiores oportunidades de crescimento e, consequentemente, maior valor de mercado, a investirem cada vez mais em ecoeficiência, propõe-se a primeira hipótese do estudo, no contexto da empresa brasileira, sugerindo-se que as oportunidades de crescimento, que refletem a criação de valor da empresa, promovem maior desempenho de ecoeficiência:

H1: Quanto maiores as oportunidades de crescimento da empresa, melhor seu desempenho de ecoeficiência corporativa.

É pertinente ainda investigar outras características empresariais que podem interferir no desempenho de ecoeficiência corporativa de empresas brasileiras de capital aberto, que comumente tem sido discutido na literatura sob a perspectiva de sustentabilidade e responsabilidade ambiental.

Existe evidência de que o tamanho da empresa pode interferir no nível de desempenho de ecoeficiência que a empresa pode estar disposta a assumir, uma vez que empresas maiores têm mais visibilidade e podem sofrer mais pressão em relação à sua postura de interferência no meio ambiente. $\mathrm{O}$ efeito positivo do porte da empresa sobre a responsabilidade ambiental empresarial tem sido postulado na literatura sob o argumento de que empresas maiores têm maior capacidade para empreender uma política socioambiental, além de serem mais cobradas pelos acionistas e sociedade em geral (ARTIACH et al., 2010; ZIEGLER; SCHRÖDER, 2010; LEE, 2011; CRISÓSTOMO; OLIVEIRA, 2016). Seguindo essa lógica defendida pela literatura, sugere-se a segunda hipótese do estudo:

\section{H2: Empresas maiores apresentam melhor desempenho de ecoeficiência.}

Outra característica relevante destacada na literatura de sustentabilidade ambiental é o impacto ambiental de empresas com maior potencial de interferência no meio ambiente, tendo em vista a intensidade de utilização de recursos naturais e de poluição. Acerca do impacto ambiental decorrente da atividade empresarial, no contexto brasileiro, é considerada a classificação proposta pela Política Nacional de Meio Ambiente através da Lei $n^{\circ} 10.165$, de 27 de dezembro de 2000, que categoriza as empresas segundo o nível de impacto de suas 
atividades, distinguindo-se neste estudo empresas que se enquadram nesta classificação sugerida, considerando os três níveis de potencial de impacto dos setores: baixo, médio e alto impacto. Dessa forma, espera-se que empresas que detenham atividades de maior potencial poluidor sejam mais pressionadas a desenvolver estratégias de responsabilidade ambiental em seus negócios, perseguindo assim um melhor desempenho de ecoeficiência em seus processos produtivos, conforme sugere evidência da literatura prévia (CRISÓSTOMO; SOUZA; PARENTE, 2012; OLIVEIRA; MACHADO; BEUREN, 2012; ROVER et al., 2012; FERNANDES, 2013). Propõe-se assim a terceira hipótese do estudo:

\section{H3: Empresas de maior impacto ambiental apresentam melhor desempenho de ecoeficiência.}

Empresas detentoras de boas práticas de governança corporativa também estariam mais compromissadas em apresentar postura mais sustentável, uma vez que um dos pilares da boa governança é a responsabilidade corporativa perante os diversos stakeholders (IBGC, 2015). Isso levaria a esforço maior das empresas na busca por melhor desempenho de ecoeficiência, pois a adoção de boas práticas de governança corporativa também acaba sendo fator propulsor de maior vantagem competitiva e ganho de reputação para a firma, o que pode ser consistente com a busca da empresa por empreender mais ecoeficiência em seu processo produtivo, seguindo evidências da literatura (HOTI, MCALEER; PAUWELS, 2007; CAVALCANTI; BOENTE, 2012). Com base na classificação utilizada pelo mercado brasileiro, esta pesquisa considera empresas que adotam melhores práticas de governança aquelas que se encontram listadas nos níveis diferenciados de governança corporativa da Bolsa de Valores (Nível 1, Nível 2 e Novo Mercado). Nessa perspectiva, propõe-se a quarta hipótese do estudo:

\section{H4: Empresas com melhores práticas de Governança Corporativa apresentam melhor desempenho de ecoeficiência.}

Por outro lado, alguns estudos argumentam que o maior endividamento da empresa leva a menor possibilidade de direcionar recursos para investir em ações de sustentabilidade e gestão ambiental. Os credores estariam em posição mais vantajosa em relação a outros stakeholders, em virtude de exercerem maior pressão e poder sobre a empresa a fim de que esta lhes destine recursos para honrar os compromissos assumidos (ARTIACH et al., 2010; TEIXEIRA; NOSSA; FUNCHAL, 2011; LAMEIRA et al., 2013; PEIXOTO et al., 2016). Nesse sentido, a empresa tenderia a um melhor desempenho de ecoeficiência na medida em que dependesse menos do financiamento de capital de terceiros, uma vez que financiar recursos via capital de terceiros pode ser mais caro para a empresa, levando a um maior comprometimento de seus recursos disponíveis frente às obrigações assumidas com credores, o que restringe o investimento em processos sustentáveis de gestão ambiental, existindo então um trade off entre endividamento e ecoeficiência corporativa (BASSEN; MEYER; SCHLANGE, 2006). Sob esta argumentação, sugere-se a quita hipótese do estudo, de que existe uma relação inversa entre desempenho de ecoeficiência e nível de endividamento da empresa brasileira.

\section{H5: Quanto maior o nível de endividamento da empresa, menor seu desempenho de ecoeficiência.}

$\mathrm{Na}$ análise do desempenho de ecoeficiência, cabe destacar ainda que existem empresas mais preocupadas e atuantes em questões relacionadas à sustentabilidade, as quais procuram sinalizar para o mercado seu compromisso com o meio ambiente e sociedade (STATMAN, 2006; BELGHITAR; CLARK; DESHMUKH, 2014). Nesse sentido, no atendimento à demanda de investidores mais exigentes quanto às práticas e políticas das empresas nas quais 
pretendem investir, seguindo uma tendência internacional, em 2005 foi criado, na então bolsa de valores de São Paulo, o Índice de Sustentabilidade Empresarial (ISE), que avalia empresas brasileiras com reconhecido comprometimento com a sustentabilidade, sendo uma ferramenta que analisa comparativamente o desempenho das empresas listadas na B3 em vista do fator sustentabilidade corporativa, pautada em eficiência econômica, equilíbrio ambiental, justiça social e governança corporativa (TEIXEIRA; NOSSA; FUNCHAL, 2011; B3, 2014; CRISÓSTOMO; OLIVEIRA, 2016). Dessa forma, como um índice de ações que busca ser um referencial para os investimentos socialmente responsáveis, espera-se que empresas que têm ações negociadas neste índice apresentem melhor desempenho de ecoeficiência corporativa, sendo proposta a sexta hipótese do presente estudo:

H6: Empresas participantes do Índice de Sustentabilidade Empresarial (ISE) apresentam melhor desempenho de ecoeficiência

\section{METODOLOGIA}

\subsection{Tipologia da pesquisa e amostra}

Segundo a classificação de Gil (2008), quanto aos objetivos da pesquisa, o presente estudo é descritivo e explicativo, pois primeiro busca-se identificar a existência de relações entre desempenho de ecoeficiência e criação de valor, para depois investigar atributos corporativos que podem influenciar o desempenho de ecoeficiência de empresas brasileiras de capital aberto. Quanto à natureza dos dados, a pesquisa se caracteriza como quali-quanti, pois se vale de análise de conteúdo prévia para mensurar desempenho de ecoeficiência, e posterior uso de procedimentos estatísticos, a fim de investigar a relação entre ecoeficiência e atributos da empresa (CRESWELL, 2003). Quanto à coleta de dados, segundo Minayo (2013), o estudo qualifica-se como documental, pois utiliza métodos e técnicas para a apreensão, compreensão e análise dos relatórios de sustentabilidade elaborados sob a responsabilidade das empresas segundo as diretrizes da Global Reporting Initiative (GRI).

A população do estudo reúne 367 companhias de capital aberto listadas na B3 em 2016. Desta população, identificou-se que apenas 100 empresas não financeiras listadas na B3 publicaram relatórios de sustentabilidade segundo as diretrizes da GRI, tendo em vista a utilização de indicadores ambientais da GRI para aplicação da metodologia de Nikolaou e Matrakoukas (2016) na mensuração do desempenho de ecoeficiência corporativa, o que consistiu na amostra inicial da pesquisa. Destaca-se que a exclusão de empresas financeiras se deve ao fato de estas apresentarem uma estrutura diferente de suas demonstrações financeiras que podem distorcer os resultados da pesquisa. No entanto, após a exclusão de mais seis empresas por conta de dados ausentes, a amostra final do estudo compreendeu apenas 94 empresas.

\subsection{Coleta e análise dos dados}

A coleta de dados secundários foi realizada por meio da obtenção de relatórios de sustentabilidade publicados pelas empresas brasileiras nas diretrizes da GRI diretamente de seus websites e do banco de dados da GRI, enquanto que os dados econômico-financeiros das empresas são obtidos no banco de dados Economática®.

Procedeu-se a uma análise de conteúdo nos relatórios de sustentabilidade, semelhantemente à metodologia proposta pelos autores Nikolaou e Matrakoukas (2016), que efetuaram análise de conteúdo referente ao desempenho ambiental em relatórios de sustentabilidade de empresas gregas no período de 2010-2012, considerando a pontuação total obtida pelos 30 indicadores ambientais propostos pelo modelo G3 da GRI, que varia numa escala de 0-120 pontos, em que quanto maior a pontuação, melhor o desempenho ambiental da 
empresa. No entanto, como o presente estudo utiliza um modelo mais recente da GRI, o G4, que entrou em vigor a partir de 2013, a análise se aplica a um total de 34 indicadores da dimensão ambiental, que resulta numa escala de 0-136 pontos para o desempenho ambiental.

Conforme evidenciado no Quadro 1, seguindo a proposta de Nikolaou e Matrakoukas (2016), a análise de conteúdo para mensurar o desempenho ambiental compreende uma escala de pontos para os indicadores ambientais dividida em: pontuação de accountability (ou transparência) e pontuação de desempenho.

Em relação à pontuação de accountability, a pontuação mínima (0) é atribuída ao indicador de sustentabilidade ambiental quando nenhuma prática foi realizada pela empresa para promover o indicador específico, já a pontuação intermediária (1) é atribuída ao indicador quando é mencionada uma informação qualitativa sobre a prática do indicador, enquanto que a pontuação máxima (2) é dada quando um valor quantitativo lhe é atribuído.

Com relação à pontuação de desempenho, o peso mínimo (0) é atribuído ao indicador quando não se relata a seu desempenho atual em comparação ao período anterior, já o peso (1) é atribuído ao indicador quando é relatado que seu desempenho no período atual foi pior em comparação ao anterior, enquanto que o peso máximo (2) é atribuído quando o indicador apresentou melhor desempenho no período atual comparado ao anterior.

Destaca-se que a análise dos indicadores ambientais apresentados pelas empresas seguindo as diretrizes da GRI consideram diversos aspectos pertinentes ao gerenciamento de recursos relacionados à sustentabilidade ambiental: materiais, energia, água, biodiversidade, emissões, efluentes e resíduos, conformidade, transporte, investimentos ambientais, avaliação ambiental de fornecedores e reclamações ambientais (Quadro 1).

Quadro 1: Escala de mensuração do desempenho ambiental por meio de indicadores da GRI

\begin{tabular}{|c|c|c|c|}
\hline \multicolumn{2}{|c|}{ Indicadores de sustentabilidade ambiental GRI } & $\begin{array}{l}\text { Pontuação de } \\
\text { Accountability }\end{array}$ & $\begin{array}{c}\text { Pontuação de } \\
\text { desempenho }\end{array}$ \\
\hline EN1-material & EN18-emissões & \multirow{17}{*}{$\begin{array}{l}\text { 0: Quando não } \\
\text { existe informação } \\
\text { relacionada } \\
\text { 1: Quando uma } \\
\text { informação } \\
\text { qualitativa é } \\
\text { mencionada } \\
\text { 2: Quando uma } \\
\text { informação } \\
\text { quantitativa é } \\
\text { mencionada }\end{array}$} & \multirow{17}{*}{$\begin{array}{c}\text { 0: Não relata } \\
\text { desempenho } \\
\text { 1: Quando o } \\
\text { desempenho é } \\
\text { pior no período } \\
\text { atual } \\
\text { 2: Quando o } \\
\text { desempenho é } \\
\text { melhor no } \\
\text { período atual }\end{array}$} \\
\hline EN2-material & EN19-missões & & \\
\hline EN3-energia & EN20-emissões & & \\
\hline EN4-energia & EN21-emissões & & \\
\hline EN5-energia & EN22-efluentes e resíduos & & \\
\hline EN6-energia & EN23-efluentes e resíduos & & \\
\hline EN7-energia & EN24-efluentes e resíduos & & \\
\hline EN8-água & EN25-efluentes e resíduos & & \\
\hline EN9-água & EN26-efluentes e resíduos & & \\
\hline EN10-água & EN27-produtos e serviços & & \\
\hline EN11-biodiversidade & EN28-produtos e serviços & & \\
\hline EN12-biodiversidade & EN29-conformidade & & \\
\hline EN13-biodiversidade & EN30-transporte & & \\
\hline EN14-biodiversidade & EN31-geral & & \\
\hline EN15-emissões & EN32-avaliação ambiental de fornecedores & & \\
\hline EN16-emissões & EN33-avaliação ambiental de fornecedores & & \\
\hline EN17-emissões & EN34-queixas e reclamações ambientais & & \\
\hline
\end{tabular}

Fonte: adaptado de Nikolaou e Matrakoukas (2016).

Dessa forma, para cada empresa são somadas as pontuações obtidas em cada um dos trinta e quatro (34) indicadores presentes nos relatórios de sustentabilidade segundo as diretrizes GRI, versão G4, chegando-se a uma pontuação máxima de 136 pontos por empresa.

\subsection{Método estatístico e modelo econométrico}

Para o alcance do objetivo da pesquisa foram utilizados instrumentos estatísticos de análise descritiva e de correlação, diferença de médias e análises de regressão linear múltipla, aplicada pelo método dos mínimos quadrados ordinários (MQO), que se mostrou como o 
modelo mais adequado. A diferença entre médias procura evidenciar a existência de diferenças entre o desempenho de ecoeficiência de diversos grupos de empresas, no que se refere às melhores práticas de governança corporativa, de sustentabilidade empresarial e ao nível de impacto ambiental. Os modelos econométricos de regressão do estudo são apresentados na Equação 1:

$$
\begin{aligned}
E C O & =\alpha+\beta_{1} \text { OportCresc }+\beta_{2} \text { Tam }+\beta_{3} \text { Endiv }+\beta_{4} \text { ImpactoMédio } \\
& + \text { BImpactoAlto }+ \text { BPráticas GC }+ \text { BPráticas } S E+\varepsilon
\end{aligned}
$$

onde: ECO representa o desempenho de ecoeficiência da empresa; OportCresc representa as oportunidades de crescimento da empresa; Tam é o tamanho da empresa; Endiv é nível de endividamento da empresa; ImpactoMédio indica se o nível de impacto ambiental da empresa é médio; ImpactoAlto indica se o nível de impacto ambiental da empresa é alto; Práticas GC representa melhores práticas de governança corporativa; Práticas $S E$ representa melhores práticas de sustentabilidade empresarial; $\alpha$ é o intercepto da reta; $\beta_{1}, \beta_{2}, \beta_{3}, \beta_{4}, \beta_{5}, \beta_{6}$ e $\beta_{7}$ são os coeficientes angulares das variáveis explicativas; e $\varepsilon$ é o termo de erro da equação.

\subsection{Variáveis do estudo}

O Quadro 2 sumariza a operacionalização das variáveis do estudo. O indicador de desempenho de ecoeficiência, variável dependente do modelo de regressão, foi operacionalizado seguindo a proposta de mensuração de Nikolaou e Matrakoukas (2016), que considera o quociente do desempenho econômico da empresa - aproximada pelo índice de rentabilidade sobre ativos (ROA) - em relação ao desempenho ambiental.

Especificamente em relação ao desempenho ambiental, são operacionalizadas duas diferentes proxies: a primeira (AM1), que segue diretamente a metodologia de Nikolaou e Matrakoukas (2016), considera o desempenho ambiental absoluto, numa escala que varia de 0 a 136 pontos; e a segunda (AM2) relativiza o desempenho ambiental absoluto pelo total de indicadores analisados, utilizada neste estudo com vistas a obter maior consistência e robustez de resultados. Com base nestas métricas para o desempenho ambiental, este estudo utiliza duas diferentes métricas para o construto de ecoeficiência corporativa (ECO):

1) o ECO1, calculado pelo quociente da rentabilidade sobre ativos normalizada (ROA_n) sobre a métrica de desempenho ambiental AM1, que foi a originalmente utilizada por Nikolaou e Matrakoukas (2016), aplicando-se técnica de normalização do índice de rentabilidade sobre ativos (ROA_n) em relação à pontuação bruta do desempenho ambiental decorrente da escala de 0-136 pontos. O ROA normalizado leva em conta as diferenças entre valores mínimos e máximos para cada observação da empresa com relação ao referido índice;

2) o ECO2, obtido pelo quociente da rentabilidade sobre ativos (ROA) sobre a métrica de desempenho ambiental AM2.

As variáveis independentes do modelo são avaliadas por meio de sete construtos. $\mathrm{O}$ primeiro são as oportunidades de crescimento cuja métrica representa a criação de valor à empresa, operacionalizada pelo $\mathrm{Q}$ de Tobin, que é comumente utilizado na literatura (VILLALONGA; AMIT, 2006; CAO; PAN; TIAN, 2011; BORTOLON, 2013). O segundo e terceiro construtos dizem respeito aos níveis de impacto ambiental alto e médio, respectivamente, segundo a classificação da Lei $n^{\circ} 10.164 / 2000$, que segmenta os setores empresariais no Brasil em níveis segundo o grau de interferência no meio ambiente, conforme já explorado em estudos anteriores (REVERTE, 2009; PEREIRA; BRUNI; DIAS FILHO, 2010; CRISÓSTOMO; SOUZA; PARENTE, 2012; SILVA et al., 2015).

$\mathrm{O}$ quarto construto refere-se às melhores práticas de governança corporativa que considera os níveis especiais de listagem na Bolsa de valores brasileira quanto aos melhores padrões em governança (nível 1, nível 2 e novo mercado), operacionalizado por variável 
dummy, seguindo propostas da literatura para a métrica (CUNHA; RIBEIRO, 2008; BRAGA; OLIVEIRA; SALOTTI, 2009; MURCIA; SANTOS, 2009; ROVER; SANTOS, 2014). Quanto ao quinto construto, que é o tamanho da empresa, este estudo acompanha a métrica que geralmente é utilizada pela literatura, cuja operacionalização consiste no logaritmo natural do total de ativos da empresa (BRANCO; RODRIGUES, 2008; AKHTARUDDIN et al., 2009; JIZI et al., 2013).

Quadro 2: Descrição das variáveis do estudo

\begin{tabular}{|c|c|c|c|c|}
\hline \multicolumn{5}{|c|}{ Variáveis independentes } \\
\hline Construtos & Métrica & \multicolumn{3}{|c|}{ Operacionalização } \\
\hline $\begin{array}{l}\text { Oportunidades de } \\
\text { crescimento } \\
\text { (OportCresc) }\end{array}$ & $\begin{array}{l}\text { Medida de criação de valor } \\
\text { (Q de Tobin) }\end{array}$ & \multicolumn{3}{|c|}{$\begin{array}{l}\text { Razão entre a soma do valor de mercado com o passivo } \\
\text { exigível e o ativo total da empresa }\end{array}$} \\
\hline $\begin{array}{c}\text { Impacto ambiental } \\
\text { alto } \\
(\text { ImpactoAlto }) \\
\end{array}$ & $\begin{array}{c}\text { Nível de impacto ambiental } \\
\text { alto, tendo em vista a Lei } \\
10.165 / 2000\end{array}$ & \multicolumn{3}{|c|}{ Dummy (0 - baixo ou médio impacto; 1 - alto impacto) } \\
\hline $\begin{array}{c}\text { Impacto ambiental } \\
\text { médio } \\
\text { (ImpactoMédio) }\end{array}$ & $\begin{array}{l}\text { Nível de impacto ambiental } \\
\text { médio, tendo em vista a } \\
\text { Lei } 10.165 / 2000\end{array}$ & \multicolumn{3}{|c|}{ Dummy (0 - baixo ou alto; 1 - médio impacto) } \\
\hline $\begin{array}{c}\text { Melhores Práticas } \\
\text { de Governança } \\
\text { Corporativa } \\
\text { (Práticas GC) }\end{array}$ & $\begin{array}{c}\text { Níveis especiais de } \\
\text { listagem da B3 (Nível 1, } \\
\text { Nível } 2 \text { e Novo Mercado) }\end{array}$ & \multicolumn{3}{|c|}{$\begin{array}{c}\text { Dummy }(0 \text { - não pertence a níveis diferenciados de GC e } 1 \\
\text { - pertence a níveis diferenciados de GC) }\end{array}$} \\
\hline $\begin{array}{c}\text { Tamanho da } \\
\text { empresa (Tam) }\end{array}$ & Total de Ativos da empresa & \multicolumn{3}{|c|}{ Logaritmo natural do total de ativos } \\
\hline $\begin{array}{l}\text { Endividamento } \\
\text { (Endiv) }\end{array}$ & Total de dívida da empresa & \multicolumn{3}{|c|}{ Razão entre a dívida total e o ativo total } \\
\hline $\begin{array}{c}\text { Melhores práticas } \\
\text { de } \\
\text { sustentabilidade } \\
\text { (Práticas } S E)\end{array}$ & $\begin{array}{c}\text { Participação de empresas } \\
\text { no Índice de } \\
\text { Sustentabilidade } \\
\text { Empresarial (ISE) da B3 }\end{array}$ & \multicolumn{3}{|c|}{ Dummy (0 - não pertence ao ISE e 1 - pertence ao ISE) } \\
\hline \multicolumn{5}{|c|}{ Variável dependente } \\
\hline Construto & Métrica & \multicolumn{3}{|c|}{ Operacionalização } \\
\hline \multirow{4}{*}{$\begin{array}{l}\text { Indicador de } \\
\text { Ecoeficiência } \\
\text { Corporativa } \\
\text { (ECO) proposto } \\
\text { por Nikolaou e } \\
\text { Matrakoukas } \\
(2016)\end{array}$} & \multirow{4}{*}{$\begin{array}{c}\mathrm{ECO}= \\
\text { Desempenho econômico / } \\
\text { Desempenho ambiental }\end{array}$} & \multirow{2}{*}{$\begin{array}{l}\text { Desempenho } \\
\text { econômico }\end{array}$} & \multirow{2}{*}{$\begin{array}{l}\text { Rentabilidade } \\
\text { sobre Ativos } \\
\quad \text { (ROA) }\end{array}$} & $\begin{array}{c}\text { Razão entre o lucro } \\
\text { líquido e o total de } \\
\text { ativos da empresa } \\
\text { (ROA) }\end{array}$ \\
\hline & & & & $\begin{array}{c}\text { ROA normalizado: } \\
\text { (ROA_n) }=136[\text { (ROAi- } \\
\text { ROAmin) / (ROAmax- } \\
\text { ROAmin)] }\end{array}$ \\
\hline & & \multirow{2}{*}{$\begin{array}{l}\text { Desempenho } \\
\text { ambiental }\end{array}$} & $\begin{array}{l}\text { Desempenho } \\
\text { Ambiental } \\
\text { Absoluto } \\
\text { (AM1) }\end{array}$ & $\begin{array}{l}\text { Escala que varia de } 0 \text { a } \\
136 \text { pontos por empresa }\end{array}$ \\
\hline & & & $\begin{array}{l}\text { Desempenho } \\
\text { Ambiental } \\
\text { Relativo } \\
\text { (AM2) }\end{array}$ & $\begin{array}{l}\text { Pontos obtidos na } \\
\text { Escala de } 0-136 / \text { total } \\
\text { de indicadores (34) }\end{array}$ \\
\hline
\end{tabular}

Fonte: elaborado pelos autores.

O sexto construto é o endividamento, cuja operacionalização consiste no quociente entre a dívida total em relação ao total de ativos da empresa, que está de acordo com a proposta de estudos anteriores (ARTIACH et al., 2010; CAO; PAN; TIAN,2011; THEISS; BAUREN, 2017). Por último, o sétimo construto é referente às melhores práticas de sustentabilidade empresarial, que considera a presença de empresas no ISE da B3, tido como um indicativo de benchmark para investimentos socialmente responsáveis no Brasil, utilizado como proxy para 
melhor desempenho em sustentabilidade por diversos estudos (CAVALCANTI; BOENTE, 2012; NOGUEIRA; GOMES, 2012; CRISÓSTOMO; OLIVEIRA, 2016; PEIXOTO et al., 2016

\section{RESULTADOS}

\subsection{Estatística descritiva}

Conforme é apresentado na Tabela 1, a amostra utilizada no estudo evidencia uma diversidade de setores elencados pela Lei 10.165/2000 como potencialmente impactantes ao meio ambiente. Observa-se maior proporção de empresas de setores classificados como de médio impacto, equivalente a $54 \%$, enquanto que menor proporção de empresas é verificada para setores de baixo impacto ambiental, em torno de $13 \%$.

Tabela 1: Distribuição de frequências setorial das empresas da amostra

\begin{tabular}{lcc}
\hline Setor & $\mathbf{N}$ & $\mathbf{\%}$ \\
\hline Baixo impacto & $\mathbf{1 2}$ & $\mathbf{1 2 , 7 6 6}$ \\
Comércio & 5 & 5,319 \\
Construção & 3 & 3,191 \\
Outros & 4 & 4,255 \\
Médio impacto & $\mathbf{5 1}$ & $\mathbf{5 4 , 2 5 5}$ \\
Telecomunicações e Eletroeletrônicos & 3 & 3,191 \\
Indústria Mecânica e Exploração de materiais & 3 & 3,191 \\
Industria de Produtos Alimentares e Bebidas & 6 & 6,383 \\
Serviços de Utilidade & 38 & 40,426 \\
Indústria Têxtil & 1 & 1,064 \\
Alto impacto & $\mathbf{3 1}$ & $\mathbf{3 2 , 9 7 9}$ \\
Indústria Metalúrgica, siderúrgica e minerais & 7 & 7,447 \\
Indústria de Papel e Celulose & 5 & 5,319 \\
Indústria Química & 5 & 5,319 \\
Petróleo e Gás & 5 & 5,319 \\
Transporte e Serviços & 9 & 9,574 \\
\hline Total & $\mathbf{9 4}$ & $\mathbf{1 0 0 , 0 0 0}$ \\
\hline Fonte:
\end{tabular}

Fonte: elaborada pelos autores.

A Tabela 2 apresenta a estatística descritiva das variáveis quantitativas do estudo. As duas variáveis que mensuram o desempenho ambiental (AM1 e AM2) evidenciam pouca variabilidade na amostra, dado seus baixos valores de coeficiente de variação.

Tabela 2: Estatística descritiva das variáveis

\begin{tabular}{lcccccc}
\hline Variável & N & Mínimo & Máximo & Média & Desvio Padrão & Coeficiente Variação \\
\hline ECO1 & 94 & 0,000 & 6,296 & 1,411 & 1,055 & 0,748 \\
ECO2 & 94 & $-0,195$ & 0,467 & 0,034 & 0,087 & 2,537 \\
Tam & 94 & 10,722 & 20,506 & 16,052 & 1,557 & 0,097 \\
Endiv & 94 & 0,002 & 1,357 & 0,614 & 0,226 & 0,369 \\
OportCresc & 94 & 0,092 & 3,515 & 1,311 & 0,601 & 0,458 \\
ROA & 94 & $-0,152$ & 0,327 & 0,033 & 0,072 & 2,172 \\
ROA_n & 94 & 0,000 & 136,000 & 52,654 & 20,551 & 0,390 \\
AM1 & 94 & 13,000 & 88,000 & 45,870 & 18,336 & 0,400 \\
AM2 & 94 & 0,382 & 2,588 & 1,349 & 0,539 & 0,400 \\
\hline
\end{tabular}

Fonte: elaborada pelos autores.

No entanto, observa-se uma média obtida para a métrica AM1 em torno de 46 pontos pelas empresas da amostra, numa escala de pontuação que chega a 136 pontos, o que se pode considerar, em geral, um baixo desempenho ambiental das empresas da amostra. Da mesma forma, a métrica AM2 também apresentou média em torno de 1,35, bem abaixo da pontuação 
máxima esperada, que chega a 4 (caso a empresa atinja a pontuação absoluta de 136, que é dividida pelos 34 itens analisados nos relatórios).

Com relação às métricas de ecoeficiência, observa-se que das duas, a ECO1 apresenta menor variabilidade na amostra, dado um menor coeficiente de variação $(0,748)$. A média apresentada pelas empresas para esta métrica é em torno de 1,41, ao passo que para a métrica ECO2 a média de desempenho de ecoeficiência gira em torno de 0,034. Para as métricas financeiras como tamanho (Tam), endividamento (Endiv) e oportunidades de crescimento (OportCresc), observam-se médias com baixa variabilidade na amostra. A média de tamanho das empresas da amostra gira em torno de 16,052, enquanto que o nível de endividamento das empresas da amostra encontra-se em torno de 0,614. Já a média das oportunidades de crescimento (OportCresc), mensurada pelo Q de Tobin, é de 1,311.

Quando se analisa as métricas de desempenho financeiro, constata-se uma baixa média amostral para o retorno sobre ativos (ROA), de aproximadamente 0,033, com maior variabilidade na amostra quando comparado com o ROA normalizado (ROA_n), que apresentou uma média próxima de 53 e coeficiente de variação de 0,39 .

A Tabela 3 traz os coeficientes de correlação para as variáveis métricas incluídas nos modelos de regressão. Os resultados indicam haver uma correlação positiva entre as duas variáveis de desempenho de ecoeficiência (ECO1 e ECO2) e oportunidades de crescimento (OportCresc).

Tabela 3: Matriz de correlação entre as variáveis métricas (Correlação de Pearson)

\begin{tabular}{lccccc}
\hline & Tam & Endiv & OportCresc & ECO1 & ECO2 \\
\hline Tam & 1 & & & & \\
Endiv & $0,300^{(* *)}$ & 1 & & & \\
OportCresc & $-0,178$ & $-0,091$ & 1 & 1 & \\
ECO1 & $-0,357^{(* *)}$ & $-0,444^{(* *)}$ & $0,345^{(* *)}$ & $0,883^{(* *)}$ & 1 \\
ECO2 & $-0,257^{(*)}$ & $-0,566^{(* *)}$ & $0,407^{(* *)}$ & $0,8 \%, 5 \%$ \\
\hline
\end{tabular}

Nota: ${ }^{*},(* *),(* * *)$ denotam, nessa ordem, a significância estatística dos coeficientes em níveis de $10 \%, 5 \%$ e $1 \%$ Fonte: elaborada pelos autores.

Por outro lado, percebe-se correlação negativa tanto do endividamento quanto do tamanho da empresa em relação às duas métricas de ecoeficiência.

A Tabela 4 mostra os resultados da comparação de médias de desempenho de ecoeficiência entre empresas da amostra que pertencem aos níveis diferenciados de governança corporativa da B3 (N1, N2 e NM) e aquelas que não pertencem a nenhum destes níveis. Constata-se um número significativo de empresas da amostra, em torno de 60, listadas nos níveis diferenciados de governança corporativa em 2016.

Tabela 4: Comparação de médias do desempenho de ecoeficiência em relação às boas práticas de governança

\begin{tabular}{lccccc}
\hline & Empresas não listadas níveis de GC & Empresas listadas dos níveis de GC & T-teste \\
\hline Variável & $\mathbf{N}$ & Média & $\mathbf{N}$ & Média & Valor $\mathbf{p}$ \\
ECO1 & 34 & 1,528 & 60 & 1,344 & 0,420 \\
ECO2 & 34 & 0,048 & 60 & 0,026 & 0,249 \\
\hline
\end{tabular}

Fonte: elaborada pelos autores.

Como é possível observar, pelos resultados dos testes de médias efetuados, constata-se não existir diferença significativa entre os dois grupos de empresas (Valor $p>0,05$ ), sugerindo desempenho de ecoeficiência similar tanto para empresas com boas práticas de governança quanto para aquelas que não figuram nos níveis diferenciados.

Os testes de comparação de médias referentes às melhores práticas de sustentabilidade empresarial, comparando o desempenho de ecoeficiência entre as empresas da amostra que 
Maria R. de Oliveira Freitas - Jackeline L. Souza - Raimundo E. S. Fontenele - Ś́lvia M. D. P. Rebouças

pertencem à carteira do ISE em 2016 e aquelas que não pertencem, são evidenciados na Tabela 5. Observa-se que apenas 27 empresas da amostra integraram carteira do ISE em 2016.

Tabela 5: Comparação de médias do desempenho de ecoeficiência em relação às melhores práticas de sustentabilidade

\begin{tabular}{lccccc}
\hline & \multicolumn{2}{c}{ Empresas não listadas no ISE } & \multicolumn{2}{c}{ Empresas listadas no ISE } & T-teste \\
\hline Variável & $\mathbf{N}$ & Média & $\mathbf{N}$ & Média & Valor $\mathbf{p}$ \\
ECO1 & 67 & 1,554 & 27 & 1,054 & $\mathbf{0 , 0 3 7}$ \\
ECO2 & 67 & 0,040 & 27 & 0,021 & 0,354 \\
\hline
\end{tabular}

Fonte: elaborada pelos autores.

Os resultados dos testes de médias evidenciam diferença estatística significativa a nível de 5\% (Valor $\mathrm{p}<0,05$ ) entre desempenho de ecoeficiência, quando se considera a métrica ECO1, de empresas mais sustentáveis, representadas pelas empresas participantes do ISE, em relação a de empresas menos sustentáveis, que compreendem as empresas não integrantes do índice.

No entanto, o resultado observado mostrou-se contrário ao esperado para a sexta hipótese do estudo (H6), uma vez que o melhor desempenho de ecoeficiência foi apresentado pelas empresas não integrantes do ISE, cuja média de 1,554 é estatisticamente superior à de empresas que participam do índice. Por outro lado, não foi encontrada diferença estatística significante entre os dois grupos de empresas para a métrica de ecoeficiência ECO2, cujos testes não rejeitam a hipótese nula de igualdade de médias (Valor p >0,05).

A Tabela 6 apresenta os resultados de uma comparação geral de médias das métricas de desempenho de ecoeficiência entre todos os grupos de setores de baixo, médio e alto impacto ambiental conforme Lei $n^{\circ}$ 10.165/2000, através de uma análise de variância (ANOVA).

Tabela 6: Comparação geral de médias entre os três setores de impacto (ANOVA)

\begin{tabular}{lccccc}
\hline Métrica & Setor de impacto & Observações & Média & F & Valor-p \\
\hline \multirow{3}{*}{ ECO1 } & Baixo & 12 & 1,574 & & 0,507 \\
& Médio & 51 & 1,480 & 0,685 & \\
& Alto & 31 & 1,234 & & \\
\multirow{2}{*}{ ECO2 } & Baixo & 12 & 0,023 & \\
& Médio & 51 & 0,052 & 2,461 & $\mathbf{0 , 0 9 1}$ \\
& Alto & 31 & 0,010 & & \\
\hline
\end{tabular}

Fonte: elaborada pelos autores.

Pelos resultados, observa-se que não há uma diferença estatisticamente significativa do desempenho de ecoeficiência, considerando as duas diferentes métricas, entre as empresas de baixo e médio impacto, assim como entre as empresas de baixo e alto impacto. No entanto, foi encontrada diferença estatisticamente significativa, embora de menor poder, a um nível de $10 \%$, considerando a métrica ECO2, entre empresas de médio e alto impacto ambiental, não havendo, portanto, indícios fortes da existência de mais elevado desempenho de ecoeficiência de empresas de médio impacto em relação às de alto impacto.

Adicionalmente, buscando-se conclusões mais robustas acerca dos achados, em consonância com procedimentos adotados por Viana Júnior e Crisóstomo (2016), realizou-se o teste de Tukey HSD que identifica quais grupos têm diferenças significativas quando comparados aos pares, conforme a Tabela 7.

Confirmando os resultados obtidos na ANOVA, verifica-se que, de fato, para a métrica ECO2, as médias diferem, com menor poder significativo a nível de $10 \%$ (Valor $\mathrm{p}<0,10$ ), quando comparadas entre os setores de alto e médio impacto, enquanto os setores de baixo e médio impacto e baixo e alto impacto não diferem entre si. 
DETERMINANTES DO DESEMPENHO DE ECOEFICIÊNCIA CORPORATIVA E A CRIAÇÃO DE VALOR ÀS EMPRESAS BRASILEIRAS

Tabela 7: Teste de Tukey HSD: Comparações múltiplas de médias do desempenho de ecoeficiência entre os três setores

\begin{tabular}{|c|c|c|c|c|c|}
\hline Métrica & (A) & (B) & Diferença entre as médias de (A) e (B) & Erro Padrão & Valor $\mathrm{p}$ \\
\hline \multirow{6}{*}{ ECO1 } & \multirow[b]{2}{*}{ Baixo } & Médio & 0,093 & 0,340 & 0,959 \\
\hline & & Alto & 0,340 & 0,360 & 0,614 \\
\hline & \multirow{2}{*}{ Médio } & Baixo & $-0,093$ & 0,340 & 0,959 \\
\hline & & Alto & 0,246 & 0,241 & 0,565 \\
\hline & \multirow{2}{*}{ Alto } & Baixo & $-0,340$ & 0,360 & 0,614 \\
\hline & & Médio & $-0,246$ & 0,241 & 0,565 \\
\hline \multirow{6}{*}{ ECO2 } & \multirow{2}{*}{ Baixo } & Médio & $-0,029$ & 0,027 & 0,536 \\
\hline & & Alto & 0,013 & 0,029 & 0,900 \\
\hline & \multirow{2}{*}{ Médio } & Baixo & 0,029 & 0,027 & 0,536 \\
\hline & & Alto & 0,042 & 0,019 & $\mathbf{0 , 0 8 4}$ \\
\hline & \multirow{2}{*}{ Alto } & Baixo & $-0,013$ & 0,029 & 0,900 \\
\hline & & Médio & $-0,042$ & 0,019 & $\mathbf{0 , 0 8 4}$ \\
\hline
\end{tabular}

Fonte: elaborada pelos autores.

\subsection{Análise multivariada}

A Tabela 8 exibe os principais resultados descritos a partir das estimativas dos modelos de regressão linear múltipla, que têm cada desempenho de ecoeficiência como variável dependente, e como variáveis explicativas os possíveis determinantes que foram hipotetizados no estudo. A ausência de multicolinearidade entre as variáveis explicativas foi evidenciada pelos valores baixos (entre 1,09 e 2,59) dos respectivos VIF (Variance Inflation Factors).

Tabela 8: Regressão linear múltipla: determinantes do desempenho de ecoeficiência

\begin{tabular}{lcccc}
\hline & ECO1 & Valor-p & ECO2 & Valor-p \\
\hline OportCresc & $\mathbf{0 , 5 5 6}$ & $\mathbf{0 , 0 0 1}$ & $\mathbf{0 , 0 5 4}$ & $\mathbf{0 , 0 0 0}$ \\
Tam & $-0,102$ & 0,126 & $-0,002$ & 0,719 \\
Endiv & $\mathbf{- 1 , 5 7 3}$ & $\mathbf{0 , 0 0 0}$ & $\mathbf{- 0 . 1 8 7}$ & $\mathbf{0 , 0 0 0}$ \\
ImpactoMédio & $-0,056$ & 0,848 & 0,029 & 0,185 \\
ImpactoAlto & $-0,258$ & 0,401 & 0,002 & 0,945 \\
Práticas GC & 0,188 & 0,381 & 0,008 & 0,633 \\
Práticas SE & $\mathbf{- 0 , 4 9 3}$ & $\mathbf{0 , 0 3 8}$ & $-0,019$ & 0,287 \\
Constante & $\mathbf{3 , 4 2 2}$ & $\mathbf{0 , 0 0 2}$ & 0,091 & 0,266 \\
\hline N & 94 & & 94 & \\
$\mathbf{R}^{2}$ & 0,363 & & 0,477 & 11,22 \\
F & 7,01 & & 0,000 & \\
Valor-p & 0,000 & & & \\
\hline
\end{tabular}

Fonte: elaborada pelos autores.

Com relação aos aspectos estatísticos dos modelos de regressão, vale informar que todos foram atendidos. A análise de variância forneceu um teste $F$ que permitiu a não rejeição da hipótese alternativa, em que a variação da variável dependente é explicada em termos globais pelas variáveis independentes, evidenciando que os dois modelos são globalmente significativos, comprovado pelo valor $\mathrm{p}=0,000$ obtido a partir da análise de variância de resíduos, com coeficientes de ajustamento dos modelos $\left(\mathrm{R}^{2}\right)$ de 0,363 e 0,477.

A homocedasticidade dos resíduos foi verificada através dos valores p para o teste de Goldfeld-Quandt, de 0,6931 para o modelo da ECO1 e de 0,6482 para o modelo ECO2. A independência dos resíduos, através do teste de Durbin-Watson, foi evidenciada por valores $\mathrm{p}$ elevados, de 0,9677 para o modelo da ECO1 e de 0,8942 para o modelo ECO2.

Os resultados das estimações que investigam os fatores determinantes do desempenho de ecoeficiência de empresas brasileiras de capital aberto demonstram significância estatística 
a nível de $1 \%$ tanto para o valor da empresa (OportCresc ) quanto para o endividamento (Endiv) nos dois modelos utilizados que considera cada uma das métricas propostas de ecoeficiência.

Estes achados sugerem que as oportunidades de crescimento (OportCresc) têm influência positiva no desempenho de ecoeficiência corporativa, corroborando para não rejeição da primeira hipótese do estudo $(\mathrm{H} 1)$. Por outro lado, percebe-se que o endividamento (Endiv) exerce influência negativa sobre o desempenho de ecoeficiência corporativa, conforme proposto na quinta hipótese do estudo (H5), sugerindo que empresas mais endividadas apresentam, de fato, menor desempenho de ecoeficiência.

Além disso, observa-se que apenas no primeiro modelo, cuja métrica de ecoeficiência é ECO1, o melhor desempenho em sustentabilidade da empresa, que leva em conta sua presença no ISE, apresentou influência negativa a nível de significância estatística de 5\% sobre o desempenho de ecoeficiência corporativa, o que contradiz a proposição da sexta hipótese do estudo (H6), que previa um efeito positivo.

Os demais fatores que figuram como variáveis explicativas do modelo (ImpactoMédio, ImpactoAlto, Práticas GC e Tam) não apresentaram nenhum efeito significativo sobre o desempenho de ecoeficiência, o que também contribui para a rejeição das demais hipóteses do estudo.

\section{DISCUSSÃO DOS RESULTADOS}

Os resultados referentes à comparação de médias do desempenho de ecoeficiência entre os diversos grupos de empresas, em geral, confirmam não existir diferença estatisticamente significativa entre as empresas quanto ao seu desempenho em ecoeficiência corporativa. A participação em segmentos diferenciados de governança corporativa, em setores de impacto ambiental, assim como no índice de sustentabilidade empresarial não diferenciou as empresas quanto ao desempenho de ecoeficiência.

Uma possível explicação para tais resultados reside no fato de que, independentemente de a empresa estar segmentada em um setor de mais alto impacto ambiental, ou de melhor governança corporativa, ou ainda de melhor desempenho em sustentabilidade, as empresas brasileiras representadas pela amostra do estudo não estão perseguindo níveis mais elevados de desempenho de ecoeficiência em seus negócios, apresentando em termos gerais uma média de baixo desempenho ambiental comparativamente ao desempenho econômico, o que difere dos achados de Nikolaou e Matrakoukas (2016) no contexto das empresas gregas, que apresentaram, concomitantemente, melhor desempenho ambiental, indicando, segundo os autores, o forte compromisso da empresa grega de cumprir com os requerimentos legais da legislação ambiental do país.

Percebe-se, pelo efeito positivo sobre o desempenho de ecoeficiência, que quanto mais oportunidades de crescimento a empresa tiver, repercutindo na geração de valor para a empresa, mais irá priorizar seu engajamento em processos de gestão ambiental de seus negócios, aprimorando-os a fim de gerar mais valor e consequentemente melhorar sua reputação perante o mercado e seus diversos stakeholders, conforme preconiza a teoria VBR (COELHO; PAVÃO; MELO, 2009). Esse efeito evidencia resultados convergentes entre o presente estudo e vários outros achados, ao também encontrarem que melhor desempenho de sustentabilidade empresarial está atrelada a maior valor de mercado da empresa (JACOBS; SINGHAL; SUBRAMANIAN, 2010; GRUPTA; BENSON, 2011; GUENSTER et al., 2011; CRISÓSTOMO; OLIVEIRA, 2016).

Além disso, é percebido o efeito negativo do endividamento sobre o desempenho de ecoeficiência corporativa, confirmando o argumento de que maior nível de endividamento da empresa restringe suas escolhas no direcionamento de recursos para investir em ações de sustentabilidade e gestão ambiental, refletindo o trade off entre endividamento e investimento em ecoeficiência (BASSEN; MEYER; SCHLANGE, 2006). Estes achados estão consistentes 
com diversos estudos (ARTIACH et al., 2010; TEIXEIRA; NOSSA; FUNCHAL, 2011; LAMEIRA et al., 2013; PEIXOTO et al., 2016).

\section{CONSIDERAÇÕES FINAIS}

A presente pesquisa teve por objetivo geral investigar os fatores determinantes do desempenho de ecoeficiência de empresas brasileiras. Para tanto, foi analisada amostra de 94 empresas não financeiras listadas na B3 que divulgaram relatório de sustentabilidade nas diretrizes da GRI no exercício de 2016.

Os resultados apontam, em linhas gerais, as oportunidades de crescimento e o nível de endividamento da empresa como importantes determinantes do desempenho de ecoeficiência corporativa, conforme detectado pelos resultados da análise de regressão. Enquanto o valor da empresa, aproximado pelas oportunidades de crescimento, apresentou efeito positivo significante sobre o desempenho de ecoeficiência, por outro lado, o nível de endividamento teve efeito negativo. Esse resultado positivo das oportunidades de crescimento encontra suporte na Teoria da Visão Baseada em Recursos (VBR), evidenciando que empresas que enfrentam maiores oportunidades de crescimento tendem a priorizar ecoeficiência corporativa em seus processos internos a fim de buscarem se diferenciar de seus concorrentes, obtendo com isso vantagem competitiva e melhor reputação frente aos diversos stakeholders. Já o efeito negativo do nível de endividamento pode ser explicado pelo trade off entre endividamento e investimento em ecoeficiência, decorrente de restrição na alocação de recursos.

Na comparação do desempenho de ecoeficiência entre os diversos grupos de empresas segmentados pelos níveis diferenciados de governança corporativa, pela participação no índice de sustentabilidade empresarial e pelo nível de impacto ambiental do setor, não se constatou uma diferença estatística significativa entre tais grupos. Ao contrário do esperado, as empresas da amostra sinalizam níveis semelhantes de desempenho de ecoeficiência, independentemente de atributos que as levem a ter mais atenção e compromisso em relação a um engajamento superior com responsabilidade ambiental e com ecoeficiência corporativa.

Acredita-se que a presente pesquisa contribui para enriquecer a bibliografia sobre ecoeficiência corporativa, principalmente ao propor uma análise mais ampla e comparativa da temática, que geralmente tem sido abordada como estudo de caso individualizado por empresa ou setor, o que foi possível a partir da aplicação de metodologia de mensuração proposta por Nikolaou e Matrakoukas (2016). Além disso, esta pesquisa avança em relação ao estudo citado por investigar a interação da ecoeficiência com a criação de valor no contexto da empresa brasileira, além investigar outros possíveis determinantes do desempenho de ecoeficiência corporativa.

Entre as limitações da pesquisa, destacam-se o exíguo período de análise, o reduzido tamanho da amostra, assim como a exploração de um único modelo proposto para mensuração de ecoeficiência. Dessa forma, como sugestão para estudos futuros, recomenda-se a utilização de um período mais longo de análise e a ampliação da amostra, além de explorar novas metodologias de mensuração da ecoeficiência e considerar outras variáveis que possam explicar o desempenho de ecoeficiência.

\section{REFERÊNCIAS}

ABREU, M. C. S.; FERNANDES, J. S.; SOARES, F. A.; SILVA FILHO, J. C. L. Evolução da conduta ambiental de empresas siderúrgicas brasileiras sob a óptica dos relatórios de evidenciação ambiental. Revista Universo Contábil, v. 4, n. 4, p. 57-76, 2008. 
AKHTARUDDIN, M.; HOSSAIN, M. A.; HOSSAIN, M.; YAO, L. Corporate Governance and Voluntary Disclosure in Corporate Annual Reports of Malaysian Listed Firms. Jamar, v. 7, n. 1, p. 1-20, 2009.

ANACLETO, C.; BEURENA, F. H.; LOHNA, V. M.; CAMPOS, L. M. S.; MIGUEL, P. A. C. Ecoeficiência e produção mais limpa: uma análise das publicações em quatro periódicos brasileiros da engenharia de produção. Sistemas \& Gestão, v. 7, n. 3, p. 476-489, 2012.

ARTIACH, T.; LEE, D.; NELSON, D.; WALKER, J. The determinants of corporate sustainability performance. Accounting and Finance, v. 50, n. 1, p. 31-51, 2010.

ASSAF NETO, A. Medidas de Criação de Valor. In: ASSAF NETO, A. Finanças Corporativas e Valor. 2. ed. São Paulo: Atlas, 2005.

BASSEN, A.; MEYER, K.; SCHLANGE, J. The Influence of Corporate Responsibility on the Cost of Capital, 2006. Working paper series. Disponível em:

<http://ssrn.com/abstract=984406>. Acesso em: 15 nov. 2017.

BELGHITAR, Y.; CLARK, E.; DESHMUKH, N. Does it pay to be ethical? Evidence from the FTSE4Good. Journal of Banking \& Finance, v. 47, n. 10, p. 54-62, 2014.

B3. ISE - Sustentabilidade Empresarial. São Paulo: B3, 2014. Disponível em: <http://www.bmfbovespa.com.br/Pdf/Indices/ISE.pdf>. Acesso em: 03 nov. 2017.

BORGES, A.J.P.; HAUSER-DAVIS, R.A.; OLIVEIRA, T.F. Cleaner red mud residue production at an alumina plant by applying experimental design techniques in the filtration stage. Journal of Cleaner Production, v. 19, n. 15, p. 1763-1769, 2011.

BORTOLON, P. M. Por que as Empresas Brasileiras Adotam Estruturas Piramidais de Controle. Revista de Administração e Contabilidade da UNISINOS, v. 10, n. 1, p. 2-18, 2013.

BRAGA, J. P.; OLIVEIRA, J. R. S.; SALOTTI, B. M. Determinantes do nível de divulgação ambiental nas demonstrações contábeis de empresas brasileiras. Revista de Contabilidade UFBA, v. 3, n. 3, p. 81-95, 2009.

BRANCO, M. C.; RODRIGUES, L. L. Factors influencing social responsibility disclosure by portuguese companies. Journal of Business Ethics, v. 83, n. 4, p. 685-701, 2008.

CAO, J.; PAN, X.; TIAN, G. Disproportional ownership structure and pay-performance relationship: Evidence from China's listed firms. Journal of Corporate Finance, v. 17, n. 3, p. 541-554, 2011.

CARROL, A.B. A Three-Dimensional Conceptual Model of Corporate Performance. Academy of Management Review, v. 4, n. 4, p. 497-505, 1979.

CAVALCANTI, J. M. M.; BOENTE, D. R. A relação de risco e retorno nas empresas integrantes do índice de sustentabilidade empresarial no período de 2008 a 2010. Revista Ambiente Contábil, v. 4, n. 1, p. 51-7, 2012. 
DETERMINANTES DO DESEMPENHO DE ECOEFICIÊNCIA CORPORATIVA E A CRIAÇÃO DE VALOR ÀS EMPRESAS BRASILEIRAS

COELHO, A. L.; PAVÃO, Y. M.; MELO, R.B. A produção científica direcionada à visão baseada em recursos (resource-based view-rbv) no Brasil e no exterior. Revista Brasileira de Docência, Ensino e Pesquisa em Administração, v. 1, n. 2, p. 177-207, 2009.

COLARES, A.C.V; MATIAS, M.A. 2014. Análise das práticas de gestão ambiental de empresas sediadas no estado de Minas Gerais - Brasil na ótica da ecoeficiência. Revista de Gestão Ambiental e Sustentabilidade - GeAS, v. 3, n. 3, p. 48-64, 2014.

CORBETT, C. J.; KLASSEN, R. D. Extending the Horizons: Environmental Excellence as Key to Improving Operations. Manufacturing \& Service Operations Management, v. 8, n. 1, p. 5-22, 2006.

CRESWELL, J. W. Research design: qualitative, quantitative, and mixed methods approaches. 2. ed. Thousand Oaks, CA: Sage, 2003.

CRISÓSTOMO, V.L.; OLIVEIRA, M.R. An Analysis of the Determinants of Corporate Social Responsibility of Brazilian Firms. Brazilian Business Review, v.13, n.4, p.72-93, 2016.

CRISÓSTOMO, V. L.; SOUZA, J. L.; PARENTE, P. H. N. Possível efeito regulatório na responsabilidade socioambiental da empresa brasileira em função da Lei n 10.165/2000.

Revista de Gestão Social e Ambiental, v. 6, n. 3, p. 157-170, 2012.

CUNHA, J. V. A.; RIBEIRO, M. S. Divulgação voluntária de informações de natureza social: um estudo nas empresas brasileira. Revista de Administração-Eletrônica (RAUSP-e), v. 1, n. 1, p. 1-23, 2008.

DODIC', S.N.; VUC`UROVIC', D.C.; POPOV, S.D.; DODIC', J.M.; RANKOVIC', J.A. Cleaner bioprocesses for promoting zero-emission biofuels production in Vojvodina.

Renewable and Sustainable Energy Reviews, v. 14, n. 9, p. 3242-3246, 2010.

ELKINGTON, J. Cannibals with forks: the triple bottom line of 21st century business. Oxford: Capstone Publishing Limited, 1997.

FERNANDES, S. M. Fatores que influenciam o disclosure ambiental: um estudo nas empresas brasileiras no período de 2006 a 2010. Revista Ambiente Contábil, v. 5, n. 2, p. 250-267, 2013.

GIANNETTI, B.F.; BONILLA, S.H.; SILVA, I.R.; ALMEIDA, C.M.V.B. Cleaner production practices in a medium size gold-plated jewelry company in Brazil: when little changes make the difference. Journal of Cleaner Production, v. 16, n. 10, p. 1106-1117, 2008.

GIL, A. C. Métodos e técnicas de pesquisa social. 6. ed. São Paulo: Atlas, 2008.

GRIFFIN, J.J.; MAHON, J.F. The Corporate Social Performance and Corporate Financial Performance Debate. Twenty-Five Years of Incomparable Research. Business \& Society, v. 36, n. 1, p. 5-31, 1997.

GRUPTA, N. J.; BENSON, C. C. Sustainability and Competitive Advantage: An Empirical Study of Value Creation. Competition Forum, v. 9, n. 1, p. 121-137, 2011. 
GUENSTER, N.; BAUER, R.; DERWALL, J.; KOEDIJK, K. The Economic Value of Corporate Eco-Efficiency. European Financial Management, v. 17, n. 4, p. 679-704, 2011.

HADEN, S.S.; OYLER, P.H.; HUMPHREYS, J.H. Historical, practical and theoretical perspectives on green management: an exploratory analysis. Management Decision, v. 47, n. 7, p. 1041-55, 2009.

HART, S.L.; AHUJA, G. Does It Pay to Be Green? An Empirical Examination of the Relationship between Emission Reduction and Firm Performance. Business Strategy and the Environment, v. 5, n. 1, p. 30-37, 1996.

HELMINEN, R. Developing tangible measures for eco-ecoficiência: the case of finish and Swedish pulp and paper industry. Business Strategy and the Environment, v. 9, n. 3, p. 196-210, 2000.

HOTI, S.; MCALEER, M.; PAUWELS, L. Measuring risk in environmental finance. Journal of Economic Surveys, v. 21, n. 5, p. 970-998, 2007.

INSTITUTO BRASILEIRO DE GOVERNANÇA CORPORATIVA. Código de Melhores Práticas de Governança Corporativa. 4. ed. Sao Paulo: IBGC, 2015.

JACOBS, B. W.; SINGHAL, V. R.; SUBRAMANIAN, R. An empirical investigation of environmental performance and the market value of the firm. Journal of Operations Management, v. 28, n. 5, p. 430-441, 2010.

JIZI, M. I.; SALAMA, A.; DIXON, R.; STRATLING, R. Corporate governance and corporate social responsibility disclosure: evidence from the US banking sector. Journal of Business Ethics, v. 125, n. 4, p. 601-615, 2013.

KAPLAN, R. S.; NORTON, D. P. A Estratégia em Ação. Rio de Janeiro: Campus, 1997.

LAMEIRA, V. J.; NESS, V. L.; QUELHAS, O. L. G.; PEREIRA, R. G. Sustentabilidade, valor, desempenho e risco no mercado de capitais brasileiro. Revista Brasileira de Gestão de Negócios, v. 15, n. 46, p. 76-90, 2013.

LEE, S. Y. Corporate carbon strategies in responding to climate change. Business Strategy Environment, v. 21, n. 1, p. 33-48, 2011.

LEHNI, M. Eco-efficiency: creating more value with less impact. World Business Council for Sustainable Development, 2000. Disponível em: < http://www.wbcsd.org> Acesso em: 15 nov. 2017.

LINS, L.; ZYLBERSZTAJN, D. Sustentabilidade e geração de valor: a transição para o século XXI. Rio de Janeiro: Elsevier, 2010.

MARGOLIS, J. D.; WALSH, J. P. Misery Loves Company: Rethinking Social Initiatives by Business. Administrative Science Quarterly, v. 48, n. 2, p. 268-305, 2003.

MINAYO, M. C. S. Pesquisa social: teoria, método e criatividade. 33. ed. Petrópolis, RJ: Vozes, 2013. 
DETERMINANTES DO DESEMPENHO DE ECOEFICIÊNCIA CORPORATIVA E A CRIAÇÃO DE VALOR ÀS EMPRESAS BRASILEIRAS

MUNCK, L.; OLIVEIRA, F.A.C; BANSI, A. C. Ecoeficiência: uma análise das metodologias de mensuração e seus respectivos indicadores. Revista de Gestão Social e Ambiental RGSA, v. 5, n. 3, p. 183-199, 2011.

MURCIA, F. D.; SANTOS, A. Fatores determinantes do nível de disclosure voluntário das companhias abertas no Brasil. Revista de Educação e Pesquisa em Contabilidade, v. 3, n. 2, p. 72-95, 2009.

NAWROCKA, D.; PARKER; T. Finding the connection: environmental management systems and environmental performance. Journal of Cleaner Production, v. 17, n. 6, p. 601-607, 2009.

NIKOLAOU, I. E.; MATRAKOUKAS, S.I. A framework to measure eco-efficiency performance of firms through EMAS reports. Sustainable Production and Consumption, v. 8, n. 4, p. 32-44, 2016.

NOGUEIRA, C. M. S.; GOMES, A. C. C. Desempenho do Índice de Sustentabilidade Empresarial (ISE) sob a perspectiva do Retorno Ajustado ao Risco: sustentabilidade gera retorno? Revista Espaço Acadêmico, v. 131, p. 89-96, 2012.

OLIVEIRA, R.; CAMANHO, A. S; ZANELLA, A. Expanded eco-efficiency assessment of large mining firms. Journal of Cleaner Production, v. 142, p. 2364-2373, 2017.

OLIVEIRA, A. F.; MACHADO, D. G.; BEUREN, I. M. Evidenciação ambiental de empresas de setores potencialmente poluidoras listadas no Índice de Sustentabilidade Empresarial (ISE). Revista de Gestão Social e Ambiental, v. 6, n. 1, p. 20-37, 2012.

PEDROSO, A.; OLIVEIRA, F. A. C.; DUTRA, I. S.; MOROZINI, J. F. Processo ou ações de ecoeficiência em empresas da cadeia produtiva agroindustrial da suinocultura de Toledo Paraná, Brasil. Revista Capital Científico- Eletrônica, v. 10, n. 1, p. 1-17, 2012.

PEIXOTO, F. M.; PAINS, M. B.; ARAÚJO, A. A.; GUIMARÃES, T. M. Custo de capital, endividamento e sustentabilidade empresarial: um estudo no mercado de capitais brasileiro no período de 2009 a 2013. RACE- Unoesc, v. 15, n. 1, p. 39-66, 2016.

PEREIRA, A. G.; BRUNI, A. L.; DIAS FILHO, J. M. Legitimidade corporativa em empresas pertencentes a indústrias ambientalmente sensíveis: um estudo empírico com empresas que negociam ações na Bovespa. Sociedade, Contabilidade e Gestão, v. 5, n. 2, p. 69-86, 2010.

REVERTE, C. Determinants of corporate social responsibility disclosure ratings by Spanish listed firms. Journal of Business Ethics, v. 88, n. 2, p. 351-366, 2009.

RODRIGUES, J. J. M.; DUARTE, M. M. R. F. R. Relato da responsabilidade social, ambiente e competitividade: enquadramento teórico. Revista Universo Contábil, v. 7, n. 4, p. 138-155, 2011.

ROVER, S.; SANTOS, A. Revisitando os determinantes do disclosure voluntário socioambiental no Brasil: em busca de robustez na mensuração da variável socioambiental. Contabilometria, v. 1, n. 2, p. 15-35, 2014. 
ROVER, S.; TOMAZZIA, E. C.; MURCIA, F.; DAL, R.I; BORBA, J. A. Explicações para a divulgação voluntária ambiental no Brasil utilizando a análise de regressão em painel. Revista de Administração, v. 47, n. 2, p. 217-230, 2012.

SALVADOR, N.N.B.; GLASSON J.; PIPER, J.M. Cleaner Production and Environmental Impact Assessment: a UK perspective. Journal of Cleaner Production, v. 8, n. 2, p. 127 $132,2000$.

SAVITZ, A.W.; WEBER, K. The triple bottom line: how today's best run companies are achieving. San Francisco: John Wiley \& Sons Inc, 2006.

SCHMIDHEINY, S. Eco-efficiency and sustainable development. Risk Management ABI/INFORM Global, v. 43, n. 7, p. 51, 1996.

SCHMIDT, P.; SANTOS, J. L.; MARTINS, M. A. Avaliação de empresas: Foco na análise de desempenho para o usuário interno: teoria e prática. São Paulo: Atlas, 2006.

SHARFMAN, M. P.; FERNANDO, C. S. Environmental risk management and the cost of capital. Strategic Management Journal, v. 29, n. 6, p. 569-592, 2008.

SILVA, M. N.; LIMA, J. A. S. O.; FREITAS, M. A. L.; SILVA FILHO, L. L.; LAGIOIA, U. C. T. Determinantes do disclosure ambiental nos relatórios de empresas listadas na B3.

Revista Ambiente Contábil, v. 7, n. 2, p. 1-15, 2015.

SOUSA, V. P.C; ANDRADE, J. M. R; CAMARA, R. P. B. Mensuração da sustentabilidade ambiental com vistas a ecoeficiência: um estudo de caso no Hotel Pirâmide em Natal/RN. Enfoque: reflexão contábil, v. 32, n. 2, p. 67-82, 2013.

STATMAN, M. Socially responsible indexes. Journal of Portfolio Management, v. 32, n. 3, p. 100-109, 2006.

TEIXEIRA, E. A.; NOSSA, V.; FUNCHAL, B. O índice de sustentabilidade empresarial (ISE) e os impactos no endividamento e na percepção de risco. Revista Contabilidade \& Finanças, v. 22, n. 55, p. 29-44, 2011.

THEISS, V.; BAUREN, I.M. Estrutura de propriedade e remuneração dos executivos. Rev. Adm. UFSM, v. 10, n. 3, p. 533-550, 2017.

ULLMAN, A.E. Data in Search of a Theory: A Critical Examination of the Relationships Among Social Performance, Social Disclosure, and Economic Performance of U.S. Firms. Academy of Management Review, v. 10, n. 3, p. 540-557, 1985.

VERFAILLIE, H. A.; BIDWELL, R. Measuring eco-efficiency: A guide to reporting company performance. London: World Business Council for Sustainable Development, 2000 .

VIANA JÚNIOR, D. B. C; CRISÓSTOMO, V. L. Nível de Disclosure Ambiental das Empresas Pertencentes aos Setores Potencialmente Agressivos ao Meio Ambiente. Revista Contabilidade, Gestão e Governança, v. 19, n. 2, p. 254-273, 2016.

VILLALONGA, B.; AMIT, R. How do family ownership, control and management affect firm value? Journal of Financial Economics, v. 80, n. 2, p. 385-417, 2006. 
ZIEGLER, A.; SCHRÖDER, M. What determines the inclusion in a sustainability stock index? A panel data analysis for European firms. Ecological Economics, v. 69, n. 4, p. 848$856,2010$. 